\title{
Construction Technology of Squat Silo Roof Supported by Cable Net and Finite Element Research
}

\author{
Hairong Huang, Guoran Hao*, Menghua Lv \\ School of Civil Engineering, Henan University of Technology, Zhengzhou, Henan 450001, China.
}

\begin{abstract}
How to cite this paper: Hairong Huang, Guoran Hao, Menghua Lv. (2022) Construction Technology of Squat Silo Roof Supported by Cable Net and Finite Element Research. Engineering Advances, 2(1), 18-25.

DOI: $10.26855 /$ ea.2022.06.002
\end{abstract}

Received: January 20, 2022

Accepted: February 14, 2022

Published: March 3, 2022

*Corresponding author: Guoran Hao, School of Civil Engineering, Henan University of Technology, Zhengzhou, Henan 450001, China.

Email: 304682333@qq.com

\begin{abstract}
Aiming at the construction technology of a large-diameter top of squat silo by a steel stranded cable net, Perform ANSYS finite element analysis, Simulate calculation of the bearing capacity of the steel stranded cable net platform built by steel strands with different tensile forces. The results are analyzed and researched and compared with the actual construction situation. It is found that after the cable net platform set up by the steel strand is subjected to the upper load, the degree of downward deflection will continue to decrease with the increase of the tensile force of the steel strand. The stress and strain will increase with the increase of the pretension of the steel strand. In actual construction, when the diameter and pitch of the steel strand are constant, the tensile force of the steel strand used should be increased as much as possible.
\end{abstract}

\section{Keywords}

Steel Strand Cable Net, Squat Silo Roof, Construction Technology, Finite Element

\section{Introduction}

The squat silo is a new type of silo that can meet the requirements of China's grain storage, which has been vigorously promoted in recent years based on China's national conditions. The squat silo has a reasonable structure, high degree of mechanization, good seismic performance, and easy to carry out thermal insulation treatment and it is one of the preferred silo roof structure forms when storing grain. The inner diameter of the squat silo is generally greater than $20 \mathrm{~m}$, and the ratio of the height of the silo body to the inner diameter of the squat silo is less than 1.5 . The main structure of the silo wall is mostly in the form of reinforced concrete, with a thickness between $250 \mathrm{~mm}$ and 270mm [1], the squat silo roof has various types such as concrete structure and steel structure.

As for the construction technology of the silo roof, the researchers have proposed the following methods: Zhao Shaowei [2] proposed an integrated construction technology for the silo wall sliding form to tow the steel structure roof. The steel structure silo roof is first assembled on the sliding formwork frame body, and then hydraulic jacks are used to raise the steel structure silo roof to the design elevation. For the large-span conical silo, Wang Jinchao [3] proposed to use sliding formwork for all the walls of the silo. After the silo wall construction is completed, the scaffolding is supported in the silo to the elevation. After the scaffolding has passed the pre-compression inspection, the subsequent roof support formwork and concrete pouring will be carried out. Zheng Youhuan [4-5] built a steel platform through the combination of the Bailey frame and the central column, and used it as a support for subsequent silo roof construction. Bi Laibin [6] proposed to combine the prefabricated silo roof structure with BIM technology to process the prefabricated components in an informatized manner, saving a lot of manpower and time, and improving the ability to control the entire project construction process.

The above-mentioned methods provide certain ideas and references for the construction technology of the squat silo roof. In this paper, combining actual engineering, and comprehensively considering the safety and economy of the engineering, a construction technology of the squat silo roof based on steel strands is proposed. 


\section{General engineering situation}

This project is a new 200,000-ton large-diameter squat silo project for a company, the silo wall adopts reinforced concrete structure, and the silo roof cover is made of cast-in-place reinforced concrete. There are 20 large-diameter shallow round silos with an inner diameter of 25 meters, arranged in a horizontal row of 5 and a total of 4 rows in vertical. The single silo capacity is 10,000 tons, total silo capacity is 200,000 tons, and the silo base covers an area of 10,331.96 square meters, building area is 10,331.96 square meters, cornice elevation is 28.5 meters, warehouse cone top platform elevation is 39.00 meters, and the building height is 39.30 meters.

\section{Selection of technical solution for the construction of squat silo roof}

\subsection{Full scaffolding support}

The traditional floor-standing full framing scaffolding support is to install full framing scaffolding as a support system for subsequent silo roof construction after the construction of the silo wall sliding form is completed.

\subsection{Based on steel strand platform support}

The steel strand platform support system refers to the use of steel strands to build an aerial steel strand cable net platform. After the erection is completed, full scaffolding is erected on the upper part of the steel strand wire net, and then the subsequent shallow round warehouse roof construction is carried out.

\subsection{Support scheme for this project}

Although the floor-standing full framing scaffolding support is simple in construction technology, it only requires traditional scaffolding operators to start the construction, but it takes a lot of formwork and pipe racks, consumes more labor, materials, and machinery, and the construction period also increases. And because the erection height is too high, its economic efficiency as well as safety needs to be improved.

Based on the support of the steel strand platform, in this way, it can greatly reduce the material used for the full framing scaffolding, improve the safety index of the frame, and reduce the amount of steel pipe used, which not only greatly saves construction costs, but also shortens the construction period, avoid the increase in construction period due to the erection and removal of a large number of steel pipes.

Through the comparative analysis of the above two support schemes, the support scheme based on the steel strand cable net platform is superior to the support scheme based on full framing scaffolding in terms of construction period and cost, so this type of support scheme is used for subsequent construction.

\section{Construction technology, construction points and process flow of shallow round silo roof}

\subsection{Construction technology of squat silo roof}

The steel strand cable net platform is overlapped with each other by steel strands with a diameter of $28 \mathrm{~mm}$. There are 21 in the horizontal direction and 21 in the vertical direction, and the spacing of each steel strand is $1,100 \mathrm{~mm}$, as shown in Figure 1. Both ends of each steel strand are fixed by a U-shaped pull ring. One end of the pull ring is pre-embedded in concrete during the construction of the silo wall. The embedded part of the pull ring is made of $\Phi 25$ round steel Q235B. After the steel strands are installed, they should be reviewed and inspected. After the inspections are correct, steel pipes will be erected on the top of the steel strand cable net platform, and safety facilities such as protective nets and platform slabs will be installed on the top of the steel pipes, avoid the risks caused by construction personnel due to high-altitude operations, as shown in Figure 2.

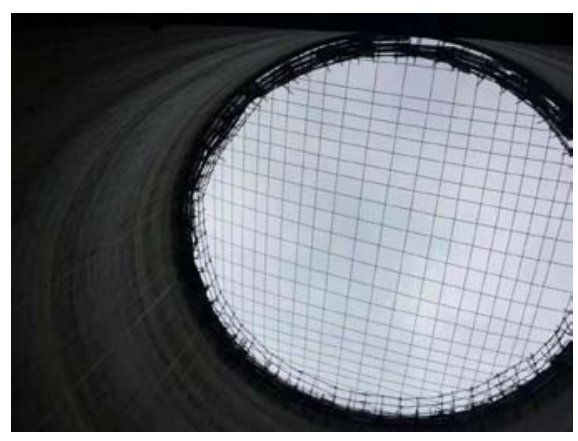

Figure 1. Arrangement of steel strands. 


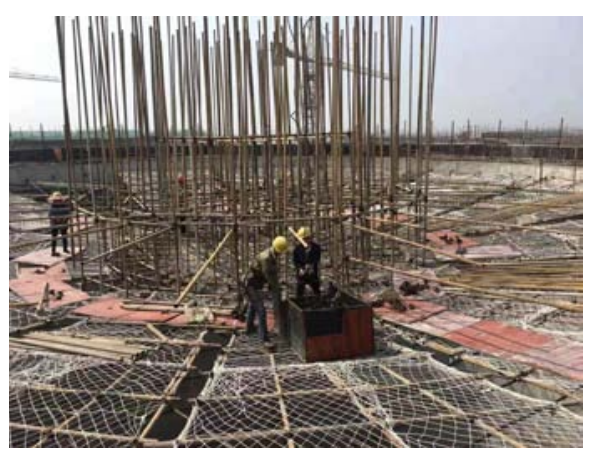

Figure 2. Arrangement of steel pipes, protective nets, platform slabs.

The vertical and horizontal spacing of the scaffolding support frame uprights on the upper part of the steel strand cable net is $1,000 \mathrm{~mm}$, horizontal bar (step distance) is $800 \mathrm{~mm}$, longitudinal distance of main pole under beam is $500 \mathrm{~mm}$, a vertical pole is added under the beam, all of which are $\Phi 48 \times 3$ steel pipes, after calculating the deflection data of the steel strand cable net caused by the upper load, the scaffolding needs to be increased by a corresponding height during construction.

After the scaffolding is erected, in the first stage, only construction of cone inclined plate, after it reaches the design strength, the construction of the cone top ring beam and the top plate is carried out. The length of the cone inclined plate is $10,761 \mathrm{~mm}$, and the thickness of the plate is $150 \mathrm{~mm}$. distribute radial steel bars evenly in the 360-degree circumference of the inclined plate, $240 \mathrm{HRB} 400$ rebars with a diameter of $10 \mathrm{~mm}$ are arranged on the top and bottom of the slab and 240 HRB400 rebars with a diameter of 8mm respectively, and one HRB400 ring rebar with a diameter of $8 \mathrm{~mm}$ is arranged every $200 \mathrm{~mm}$ on the top and bottom of the slab.

The second phase was carried out for the construction of the ring beam as well as the top slab. The upper and lower parts of the upper ring beam are each equipped with 7 HRB400 rebars with a diameter of 25mm, 8 HRB400 rebars with a diameter of $20 \mathrm{~mm}$ on each side, one HRB 400 rebar with a diameter of $10 \mathrm{~mm}$ is arranged every $300 \mathrm{~mm}$ on the cut surface. The top plate is $6,500 \mathrm{~mm}$ long and $150 \mathrm{~mm}$ thick, a HRB400 steel bar with a diameter of $10 \mathrm{~mm}$ is arranged every $100 \mathrm{~mm}$ on the upper and lower part of the top plate. The template adopts a $12 \mathrm{~mm}$ thick wooden template, and the template is fixed by a lump of wood.

The inclined plate, roof and ring beam of squat silo are all made of C35 concrete mixed with $10 \%$ U-shaped micro-expansion agent (instead of cement). The number of maintenance days should be more than 14 days, and the winter construction should pay attention to heat preservation. The sequence of concrete pouring is: from bottom to top, layered and continuous pouring, pouring the upper layer of concrete before the initial setting of the lower layer of concrete, the slump of the concrete needs to be controlled. The formwork can be removed after the concrete strength of the inclined plate, roof and ring beam reaches the standard. The removed steel pipes and formwork are transported to the roof of the shallow silo through reserved holes, and then transported to the ground by tower crane. If some components are not easy to remove, a crowbar can be used to pry slightly from the bottom to ensure that each part of the concrete is not damaged by demolition.

After the construction is completed, the scaffold should be dismantled first. The dismantling operation must be carried out from top to bottom layer by layer. Simultaneous operation is strictly prohibited. After the scaffold is removed, use gas welding to cut the embedded parts, and then use the electric hoist to lower the steel strand to the ground, here, attention should be paid to keeping the speed of the electric hoist consistent to ensure safety.

\subsection{Operation Essentials}

(1) All materials and installation equipment must meet the specifications, standards, and design requirements, and must be inspected before entering the site, it is strictly forbidden to use and install uninspected or unqualified materials, equipment, and components.

(2) All steel strands, pull rings, steel pipes and other materials are ready on site, and technical clarifications will be made to the relevant management personnel, technicians, and workers involved in the construction.

(3) Need to prepare safety nets, platform boards and other safety supplies.

\subsection{Process flow}

Preliminary preparation $\rightarrow$ Silo wall construction $\rightarrow$ Installation of pulling ring $\rightarrow$ Steel strand arriving at specified position $\rightarrow$ Installation of steel strand $\rightarrow$ Review and acceptance $\rightarrow$ Build scaffolding $\rightarrow$ Binding rebar $\rightarrow$ Installation formwork $\rightarrow$ Pouring concrete $\rightarrow$ Remove the formwork after reaching the specified strength $\rightarrow$ Removal of steel strands 


\section{ANSYS software modeling analysis}

In the actual construction, because the construction process is all done on the steel strand cable net platform, so the platform will be subject to the upper construction load will produce a certain amount of deflection, this paper according to the actual project, the use of ANSYS finite element software simulation, apply different pretension force to the strand, a comparative analysis of the degree of deflection of the steel strand cable net when subjected to load.

\subsection{Define unit type}

ANSYS in the 2020R1 version of the new cable unit Cable280, the unit is suitable for the simulation of medium to very fine cable structure, for the civil engineering industry, very suitable for the simulation of tensile cable, so here the prestressed steel strand selected cable unit Cable280.

Since the connection between the steel strand and the squat silo wall is to be considered, Shell181 unit is chosen for the squat silo wall and the squat silo wall thickness is defined for it with the sectype, secdata command.

\subsection{The data required for modeling}

The modulus of elasticity of prestressing strand is $1.95 \times 1,011 \mathrm{~N} / \mathrm{m}^{2}$, the material density is $7,850 \mathrm{~kg} / \mathrm{m}^{3}$, Poisson's ratio is 0.3 ; the modulus of elasticity of concrete of silo wall is $3 \times 1,010 \mathrm{~N} / \mathrm{m}^{2}$, the material density is $2,600 \mathrm{~kg} / \mathrm{m}^{3}$, Poisson's ratio PRXY is 0.2 , and the thickness of silo wall is $0.25 \mathrm{~m}$. This paper studies the deflection of the steel stranded cable net and the change of stress when different pretension force $\mathrm{Ft}=90 \mathrm{kN} \sim 150 \mathrm{kN}$ are applied to the prestressing strand.

\subsection{Solid modeling and meshing}

First, create a cylinder. For the prestressed steel strand, select the working plane, use the *do cycle command to cut horizontally and vertically, and then delete the excess body and the bottom surface. The steel strand adopts the overlapping form. Because the silo wall uses shell181 unit, so just define the thickness of the remaining side.

The prestressed steel strands are meshed according to each segment, as shown in Figure 3.The meshing length of the silo wall is determined by the node where the wall of the silo is in contact with the steel strand, the height is $1 \mathrm{~m}$, and the thickness is $0.25 \mathrm{~m}$ of the wall of the silo, as shown in Figure 4.

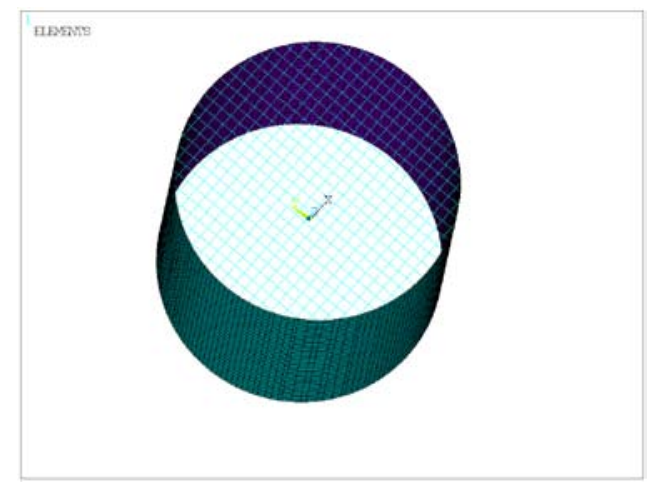

Figure 3. Meshing of steel strands.

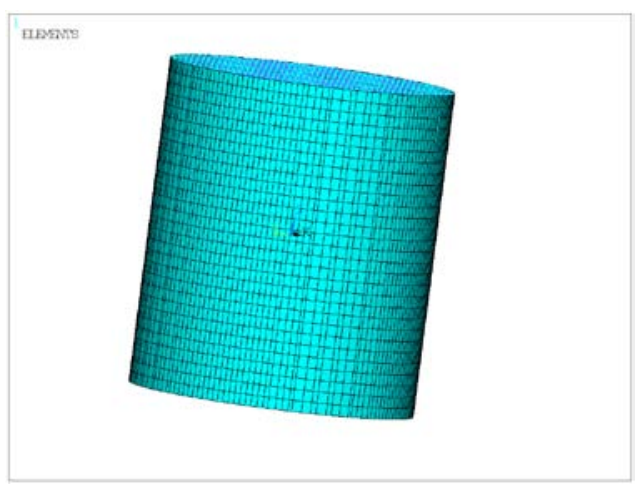

Figure 4. Meshing of the silo wall. 


\subsection{Applying restraints and loads}

In reality, the lower part of the silo wall is fixed. To simulate the actual situation of the silo, a fixed end constraint must be applied to the lower part of the cylinder wall to limit its displacement in the $\mathrm{X}, \mathrm{Y}$, and $\mathrm{Z}$ directions. For the dead weight of the silo, the ACEL command is used to apply the vertical upward gravitational acceleration.

\subsection{Applying load to prestressing steel strands}

Load application can be used to reduce the temperature of the prestressed steel strand to make it shrink, that is, set an initial temperature for the steel strand, and give a temperature drop value to make the steel strand produce a shrinkage deformation, this initial strain will cause The steel strand produces pretension force, thereby generating prestress [7], the formula is as follows:

$$
\Delta T=\frac{F}{\alpha E A}=\frac{\sigma}{\alpha E}
$$

In the formula, $\Delta \mathrm{T}$ is the applied temperature drop value; $\mathrm{F}$ is the average pretension force value of the prestressed steel strand; $\sigma$ is the prestress value; A is the cross-sectional area of the prestressed tendon; E is the elastic modulus of the prestressed tendon; $\alpha$ is the linear expansion coefficient of the prestressed steel strand.

After calculation, the required cooling values for different tensile forces are shown in Table 1.

Table 1. Lowering temperature values required for different pretension force

\begin{tabular}{cc}
\hline pretension force $(\mathrm{kN})$ & cooling values $\left({ }^{\circ} \mathrm{C}\right)$ \\
\hline 90 & 65.179 \\
100 & 72.421 \\
110 & 79.663 \\
120 & 86.905 \\
130 & 94.147 \\
140 & 101.389 \\
150 & 108.631 \\
\hline
\end{tabular}

\subsection{Load calculations}

Calculate the required load on the upper part of the stranded wire.

(1) Concrete load of cone silo roof structure (standard value)

Q1k=67×24=1608kN

(2) Rebar load (standard value)

Q2k $=67 \times 1.1+20 \times 1.5=103.7 \mathrm{kN}$

(3) Formwork load (standard value)

$\mathrm{Q} 3 \mathrm{k}=(364.38+44) \times 0.3+2.6 \times 25.4 \times 0.3=142 \mathrm{kN}$

(4) Steel pipe (fastener) supporting load (standard value)

A total of 381 main poles: look up the table to calculate the self-weight per meter of the pole structure $0.2378 \mathrm{kN} / \mathrm{m}$

The structural self-weight value of the steel pipe pole under the beam is $0.15 \mathrm{kN} / \mathrm{m}$

(a) Load of steel pipe support under the slab (weight converted by volume)

The volume of the $6.45 \mathrm{~m}$ cylinder: $2,450.6 \mathrm{~m}^{3}$

Filling volume of the lower frame tube of the cone: $1,450 \mathrm{~m}^{3}$

Steel pipe weight $=1450 / 2451 \times(381 \times 0.2378 \times 6.45)=345.8 \mathrm{kN}$

(b) The weight of the dense steel pipe at the lower part of the beam $=100 \times 5.5 \times 0.15=82.5 \mathrm{kN}$

The total weight of the steel pipe bracket Q4k=345.8+82.5 $=428 \mathrm{kN}$

(5)Construction load (the construction load on the top of the silo is mainly the construction personnel, this project is considered based on 30 people, and the safety factor of 3.0 is adopted)

$\mathrm{Q} 5 \mathrm{~K}=30 \times 3=90 \mathrm{kN}$

The results are shown in Table 2. 
Table 2. The loads to be carried by the steel stranded cable net

\begin{tabular}{ccccc}
\hline Load position & Load name & standard value $(\mathrm{kN})$ & partial coefficients & Design value $(\mathrm{kN})$ \\
\hline \multirow{3}{*}{ Silo roof } & Rebar load & 103.7 & 1.3 & 134.8 \\
& Concrete load & $1,608.0$ & 1.3 & $2,090.4$ \\
& Formwork load & 142.0 & 1.3 & 184.6 \\
& Scaffolding load & 428.0 & 1.3 & 556.4 \\
& Construction load & 90.0 & 1.5 & 135.0 \\
\hline
\end{tabular}

\section{Analysis of post-processing calculation results}

Through the calculation of ANSYS software, after the steel strands with different tensile forces are subjected to the upper load, the degree of deflection of the cable net, the deformation of the cylinder wall and the stress and strain are analyzed.

\subsection{Analysis of deformation data of cable net and silo wall after loading of steel strand with different pretension force}

When $\mathrm{Ft}=90 \mathrm{kN} \sim 150 \mathrm{kN}$, the steel strand cable net under the deflection degree change graph, as shown in Figure 5.

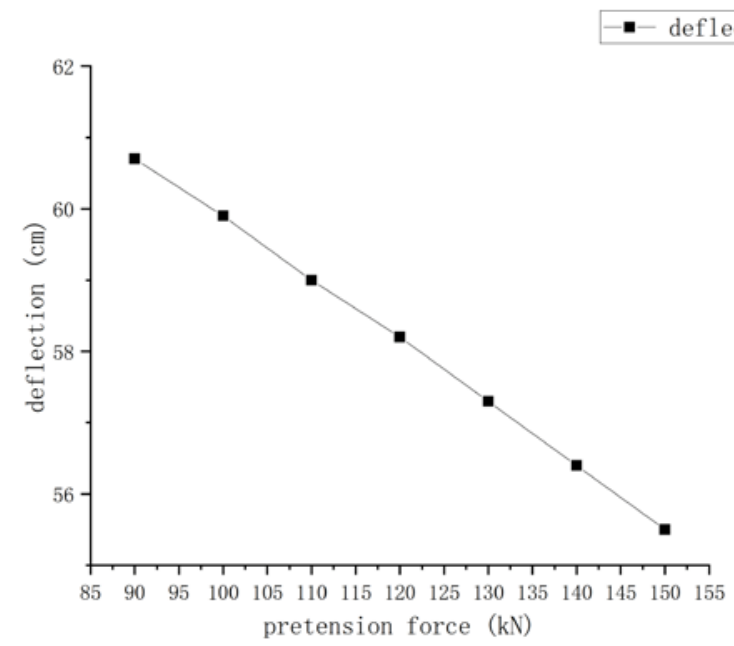

Figure 5. Deflection of steel stranded cable net with different pretension force.

From Figure 5 can be seen: the greater the tension of the steel strand, the steel strand cable net in the upper load by the lower deflection degree, in the actual construction, should try to increase the pretension force of the steel strand, but also to consider the safety angle, to avoid the pretension force is too large, there may be strand damage and so on.

Through the calculation, when $\mathrm{F}_{1}=90 \mathrm{kN}$, the steel strand cable net at the center of the maximum deflection of $60.7 \mathrm{~cm}$, when $\mathrm{F}_{2}=150 \mathrm{kN}$, the steel strand cable net at the center of the minimum deflection of $55.5 \mathrm{~cm}$. In the field before the actual construction, the average deflection data for the experiment is $30 \mathrm{~cm}$, through analysis, consider the actual and simulation of the causes of error as follows:

(1) During the field experiment, only the standard value of the actual load on the upper part of the steel strand cable net was stacked, and the partial coefficients of 1.3 for constant load and 1.5 for live load was not considered.

(2) Field experiments in the erection of steel strand cable net, due to the distance of each strand is too large, the center point of the net will have a certain degree of decline, while the simulation is the ideal situation.

When the minimum tensile force $\mathrm{F}_{1}=90 \mathrm{kN}$, the steel strand cable net is subjected to the upper load and the maximum deformation of the silo wall is $1.72 \mathrm{~cm}$. When the maximum tensile force $F_{2}=150 \mathrm{kN}$, the steel strand cable net is subjected to the upper load and the maximum deformation of the silo wall is $1.68 \mathrm{~cm}$. For the shallow circular silo with $25 \mathrm{~m}$ diameter and $0.25 \mathrm{~m}$ thick silo wall, the deformation is small and will not affect the actual construction. The results are 
shown in Figure 6 and Figure 7.

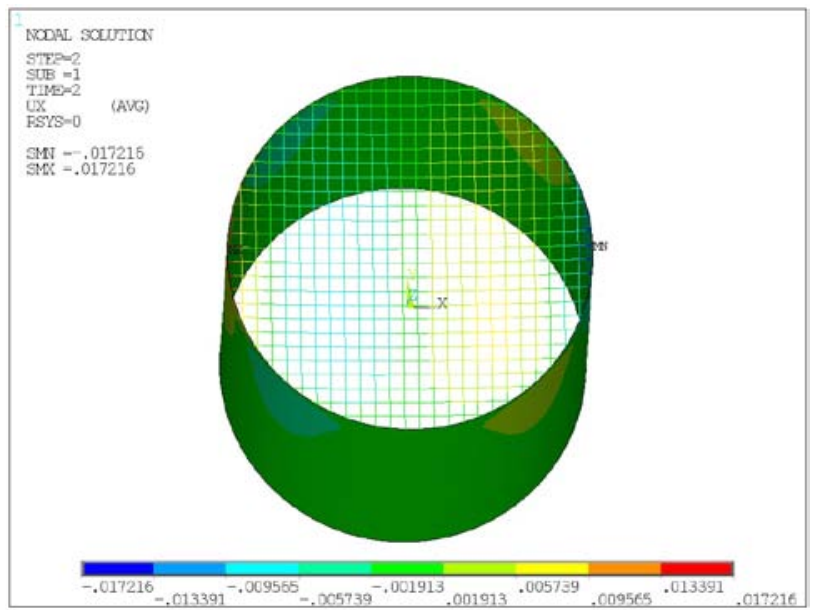

Figure 6. Deformation of the silo wall when the pretension force is $90 \mathrm{kN}$.

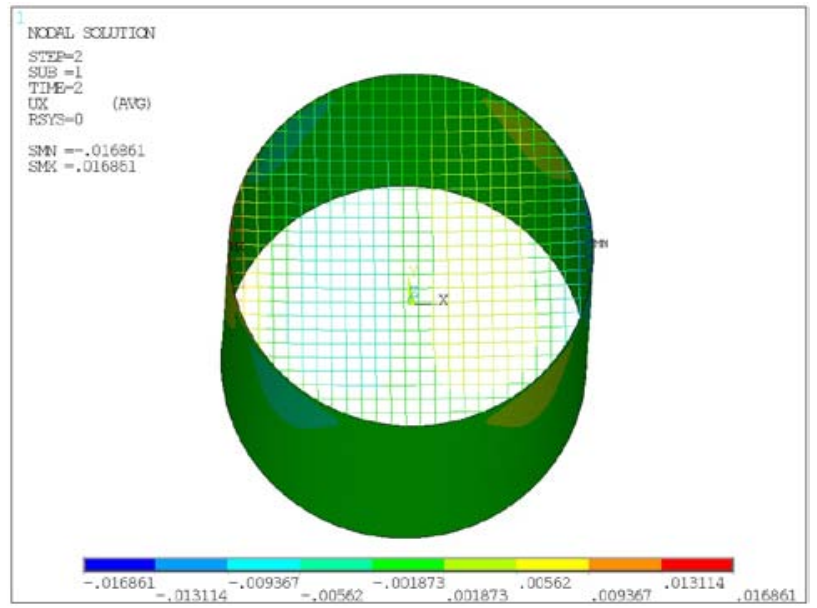

Figure 7. Deformation of the silo wall when the pretension force is $150 \mathrm{kN}$.

\subsection{Analysis of stress strain data after loading of steel strands with different pretension force}

When $\mathrm{Ft}=90 \mathrm{kN} \sim 150 \mathrm{kN}$, the steel strand cable net stress, strain change diagram, as shown in Figure 8, Figure 9.

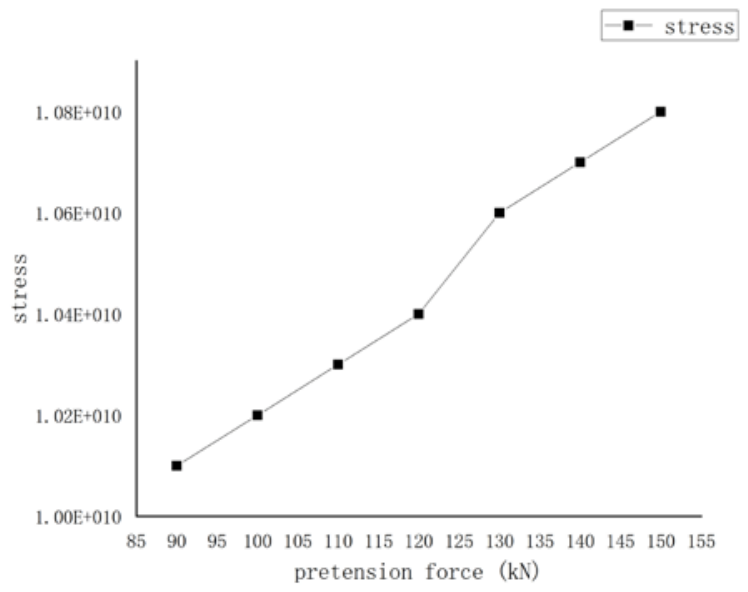

Figure 8. Stress variation corresponding to different pretension force. 


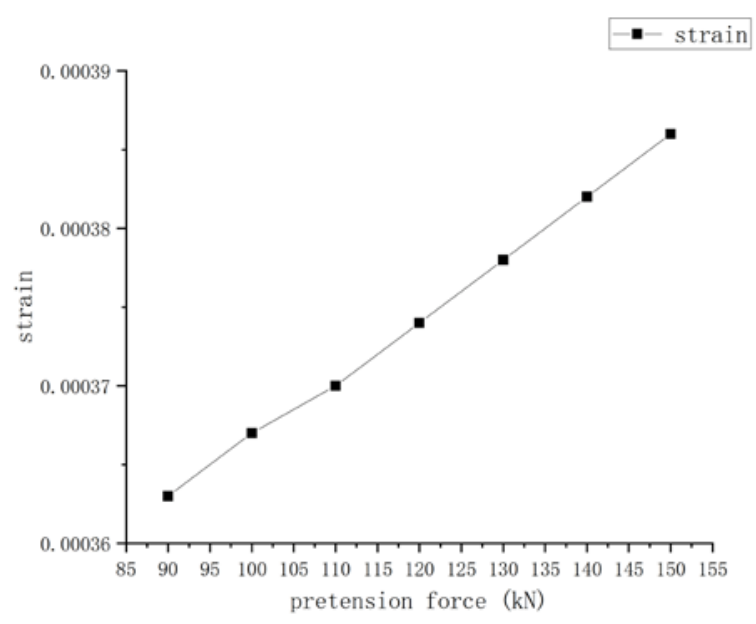

Figure 9. Strain variation corresponding to different pretension force.

From Figure 8 can be seen: for different pretension force of the strand, the steel strand cable net is subjected to the upper load, with the increasing pretension force, the stress on the silo wall is also increasing, the pretension force increases by $10 \mathrm{kN}$, the stress increases by $0.1 \mathrm{E}+09 \mathrm{~Pa}$.

From Figure 9 can be seen: for different pretension force of the strand, the steel strand cable net is subjected to the upper load, with the increasing pretension force, the strain on the silo wall is also increasing, the pretension force increases by $10 \mathrm{kN}$, the strain increases by $0.4 \mathrm{E}-05$.

\section{Conclusion}

In the pretension force of $90 \mathrm{kN} \sim 150 \mathrm{kN}$, the steel strand cable net deflection degree will continue to decrease with the increase in pretension. Stress, strain will increase with the increase in pretension. So the actual construction, in the strand distance and strand diameter of a certain situation, should try to improve the pretension force of the steel strand. However, considering that after the tension reaches a certain strength, the steel strand will be damaged, so it is necessary to combine with the actual, comprehensive consideration of other factors.

\section{References}

[1] Wang Haipeng, Liu Yang, Jin Mei. (2008). Research status and development trend of safe grain storage in shallow silo [J]. Grain Storage, 2008, 37(6): 27-31.

[2] Zhao Shaowei, Xia Lichun. (2012). Construction process and monitoring of large-diameter silo's sliding-form towed steel structure roof [J]. Journal of Tianjin Chengjian University, 2012(4): 254-257.

[3] Wang Jinchao, Li Xiaoqiang, Shan qin. (2016). Construction Technology of Large Span Conical Roof Silo [J]. Construction Technology, 2016, 45(11): 20-23.

[4] Zheng Youhuan, Zhang Chunwei, Zhou Zhaohui. (2020). Application of Bailey Frame Steel Platform Support System in Construction of Silo Roof Structure [A]. Zhejiang Society of Civil Architecture. The 26th Civil Engineering And Construction Technology Exchange Conference of Six Provinces and one City in East China (Volume 1) [C]. Zhejiang Society of Civil Architecture: Construction Technology Editorial Department, 2020: 4.

[5] Jin Ze, Xu Feng, Wu Yingqiang. (2020). Design and Construction of Steel Truss Supporting System on the Roof of Shallow Round Warehouse [J]. Building Construction, 2020, 42(07): 1200-1203.

[6] Bi Laibin. (2019). Research on the Standardized Design and Construction Technology of the Roof Structure of the Assembled Silo Based on BIM Technology [D]. Henan University of Technology, 2019.

[7] He Lin, Wang Jialin. (2015). Equivalent load-real reinforcement cooling method for simulating effective prestress [J]. Journal of Highway and Transportation Research and Development, 2015, 32(11): 75-80. 